\title{
Influence of surface roughness on cold formability in bending processes: a multiscale modelling approach with the hybrid damage mechanics model
}

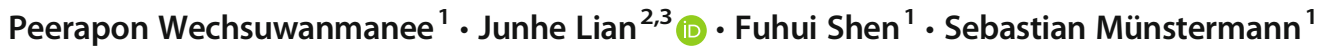

Received: 30 November 2019 / Accepted: 7 July 2020 / Published online: 19 July 2020

(C) The Author(s) 2020

\begin{abstract}
Experimental and numerical investigations on the description of cold formability of extra abrasion-resistant steel considering surface roughness effects were performed in this study. A novel multiscale numerical approach to quantitatively evaluate the impacts of surface roughness on the cold formability/bendability of heavy plates was proposed and verified. The macroscopic ductile damage behavior of the investigated steel was described by a hybrid damage mechanics model, whose parameters were calibrated by notched round-bar (NRB) tensile tests and single-edge notched bending (SENB) tests. The surface roughness was characterized by confocal microscopy and statistically incorporated into a two-dimensional representative volume element (RVE) model. For the assessment of the bendability of heavy plates in the component level, the critical ratio between the punch radius and the sample thickness $r / t$ in three-point bending tests was predicted and compared with experimental results. After the surface roughness effects were taken into consideration, a significant improvement in the predicted results was achieved. A good match between the simulation and experimental results confirmed the indispensable influences of surface roughness on the bendability of steels and validated the efficiency of the multiscale simulation approach in the quantitative description of surface roughness affected ductile damage evolutions.
\end{abstract}

Keywords Cold formability $\cdot$ Bendability $\cdot$ Ductile damage $\cdot$ Surface roughness $\cdot$ Extra abrasion-resistant steel

\section{Introduction}

In order to improve the lightweight engineering potential, materials scientists and metallurgists have developed different generations of high strength steels $[1,2]$. Due to the development of materials forming technology, more demands on the processing properties of these materials have been raised in addition to their obviously enhanced mechanical properties in terms of strength and toughness [2].

Junhe Lian

junhe.lian@aalto.fi; lianjh@mit.edu

1 Steel Institute, RWTH Aachen University, Intzestraße 1, 52072 Aachen, Germany

2 Advanced Manufacturing and Materials, Department of Mechanical Engineering, Aalto University, Puumiehenkuja 3, 02150 Espoo, Finland

3 Impact and Crashworthiness Lab, Department of Mechanical Engineering, Massachusetts Institute of Technology, 77 Massachusetts Avenue, Cambridge, MA 02139-4307, USA
Surface integrity, including surface roughness, residual stresses, and microstructure of surface layers, is a significant factor in the determination of the degradation and failure process of materials [3-6]. Concerning the effects of surface roughness on the fracture properties of metallic materials, numerous studies have been focused on the impacts of surface roughness on the fatigue behaviors due to the specified fracture mechanism, which has a natural dependence on the surface quality $[3,4,7-10]$. Surface roughness is usually treated as a geometrical surficial defect and a source of stress concentration. A popular engineering method in the quantitative evaluation of surface roughness effects on fatigue strength is to introduce some empirical surface modification factors $[8,9]$. However, this method is sometimes inadequate. Under monotonic loading conditions, surface roughness is believed to have an important influence on the mechanical and ductile damage properties of metallic materials as well. For example, during bending experiments, the cold formability, or bendability in particular, of heavy plates are significantly affected by the surface roughness of the specimens. However, in the open literature, there is hardly any research on the quantitative 
assessment of the influences of surface roughness on the bendability of steels [3]. Therefore, the major aim of this study is to propose a numerical approach to quantify surface roughness affected ductile damage behavior of steels. Multiscale modeling approaches have been an efficient method to correlate the macroscopic mechanical properties with specific microscopic features, such as phase distribution [11, 12], grain shape [13], and texture [14]. In order to numerically investigate the ductile damage behaviors of extra abrasion-resistant steel (XAR 450) considering surface roughness effects, a multiscale modeling approach has been proposed in this study. The macroscopic ductile damage is described using a phenomenological hybrid damage mechanics model $[15,16]$, while the surface roughness is characterized by a twodimensional sub-model.

The ductile damage behavior of advanced high strength steels with improved toughness is usually characterized by three different stages: void nucleation, void growth, and void coalescence which leads to the final failure of the component [17-19]. Tremendous research works have been performed on the precise characterization and description of ductile damage behavior of metallic materials [17, 20-26]. Due to tireless efforts of the peers, several damage mechanics models have been developed and applied [15, 18, 21-23, 26-37]. Based on different assumptions of whether damage has an impact on plasticity, these damage mechanics models can be classified into two groups, namely the coupled and uncoupled models [21].

In the coupled models, the effect of damage on plastic flow is taken into consideration. The Gurson family models $[34,36$, 38-48] and the continuum damage mechanics (CDM) models $[27,49-54]$ are the two famous types of coupled models that are widely applied. Based on the fundamental work of Gurson, Tvergaard, and Needleman [36, 43-45], the void volume fraction variable as a measure of damage effect has been integrated into the yield potential and the void nucleation, evolution and coalescence effect has been considered in the GTN model. Later on, further developments of the GTN model have been made in order to consider the void distribution effect [39], the void shape change [38, 40, 41], the void rotation effect $[25,38,41]$ and the void shear effect dependent on the third invariant of the stress deviator [42, 47, 48]. Another famous approach in coupling damage and plasticity are the socalled CDM based models [27], which are derived within the framework of thermodynamics. In the CDM models, an integral damage variable is introduced to quantify the degree of material degradation [27]. Further developments of the CDM models have been conducted by many researchers to consider kinematic hardening, anisotropy, and crack closure effects due to its relatively easy implementation [51-54]. The macroscopic consideration of damage in coupled models restricts their capability in the description of microscopic damage mechanisms. Furthermore, due to the aforementioned modifications, more parameters are included and the calibration procedure becomes increasingly difficult and time-consuming [37].

Part of these disadvantages of the coupled damage models is to some extent overcome by adopting the uncoupled approach, in which no interaction between damage and plasticity is assumed. Recently, it has been a major trend that the ductile fracture equivalent plastic strain of metallic materials is characterized as a weighted function of the stress triaxiality and Lode angle parameter. Remarkable research work has been done by Bao and Wierzbicki [20], who have performed a systematic study on a series of fracture specimens with different geometries covering a wide range of stress states. They have constructed a clear fracture locus of the Al 2024 T351 alloy. Since then several fracture criteria $[29,31,55,56]$ which consider the influence of Lode angle have been proposed and developed. Even though these uncoupled ductile fracture criteria can provide high accuracy and easy calibration procedure, they suffer from a common disadvantage that the various microscopic damage mechanisms are not properly revealed.

Based on the above-mentioned corresponding advantages and disadvantages of coupled and uncoupled damage mechanics models, Lian et al. [15] have proposed a new hybrid damage mechanics model, which is extending the uncoupled fracture model into the coupled framework, where the damage initiation strain instead of the fracture strain is adopted [11]. The hybrid damage mechanics model can provide high accuracy not only in the characterization of the damage initiation and failure strains but also in the description of the damage evolution under various applications, such as for dynamic loading [57, 58], anisotropic fracture [59] and even cleavage fracture [60]. In the present research, the model is applied to assess the cold formability of a high-strength steel with extraordinary abrasion resistance.

For the numerical modeling of surface roughness, some researchers have used the finite element method (FEM) in which the surface roughness is represented by a curved surface boundary $[7,61]$. However, Considering the huge length scale difference between roughness characteristics and component applications in this study, a novel multiscale approach based on the sub-modeling concept has been applied to precisely reveal the influences of localization in the finer level of the investigated material. The sub-model is a mesoscale volume element which contains sufficient information of the given materials without losing the computational efficiency for micromechanics based simulations [62-65].

The macroscopic damage related parameters are calibrated by a numerical and experimental study of single edge notched bending (SENB) tests. The micro-level features, in particular surface roughness profiles, are characterized by confocal microscopy and statistically incorporated into the twodimensional sub-model. On the industrial scale, the critical ratio between the punch radius and the sample thickness $r / t$ 

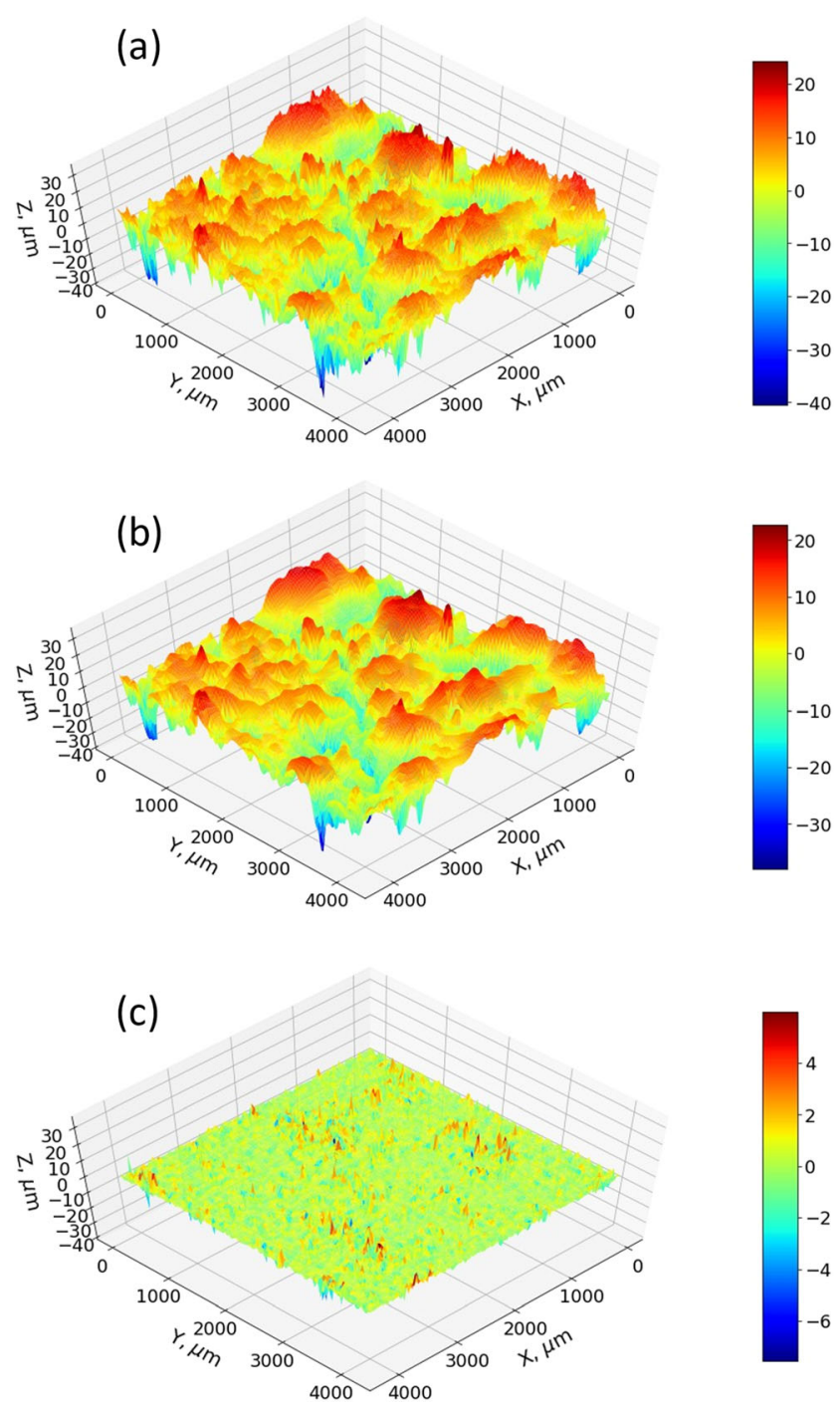

Fig. 1 3D surface characterization: (a) raw surface in 3D (b) extracted waviness profile and (c) extracted roughness profile

in the three-point bending tests is a characteristic value for the assessment and evaluation of the bendability of heavy plates [16]. While taking the surface roughness effects into consideration, a good match between the predicted and experimental results of the critical values of the $r / t$ ratio in the three-point bending tests has proved the efficiency of the proposed method in bridging multi-scale simulations.

\section{Numerical modeling}

\section{Material model}

The hybrid damage mechanics model that describes the damage and fracture behavior in macroscopic level considers the local conditions of the structure, i.e., local equivalent plastic strain $\bar{\varepsilon}^{p}$ and local stress-states. For the sake of completeness, the brief equations of the model [15] are given below. Given three principal stresses $\sigma_{1}, \sigma_{2}$, and $\sigma_{3}$, the three invariants read:

$p=-\sigma_{m}=-\frac{1}{3}\left(\sigma_{1}+\sigma_{2}+\sigma_{3}\right)$

$q=\bar{\sigma}=\sqrt{\frac{1}{2} \cdot\left[\left(\sigma_{1}-\sigma_{2}\right)^{2}+\left(\sigma_{2}-\sigma_{3}\right)^{2}+\left(\sigma_{3}-\sigma_{1}\right)^{2}\right]}$

$r=\left[\frac{27}{2} \cdot\left(\sigma_{1}-\sigma_{m}\right)\left(\sigma_{2}-\sigma_{m}\right)\left(\sigma_{3}-\sigma_{m}\right)\right]^{\frac{1}{3}}$

By the definition of these invariants, the variables which define stress-states are stress triaxiality $\eta$ and Lode angle $\theta$ defined by:

$\eta=-\frac{p}{q}$

$\theta=\frac{1}{3} \cdot \arccos \left[\left(\frac{r}{q}\right)^{3}\right]$

Due to symmetry of the Lode angle, it can be characterized in the range of $0 \leq \theta \leq \frac{\pi}{3}$. The normalized Lode angle is called Lode angle parameter and reads:

$\theta=1-\frac{6 \theta}{\pi}$

As the strain develops during loading applied, the constitutive model that governs mechanical behavior does not take any effect on any type of damages. The damage $D$ can cause a softening effect onto the yield stress $\sigma_{y}$. The yield potential $\Phi$ is represented by:

$\Phi=\bar{\sigma}-(1-D) \sigma_{y} \leq 0$

At an instant that the damage initiation criterion is fulfilled, the yield potential considers the softening effect from ductile

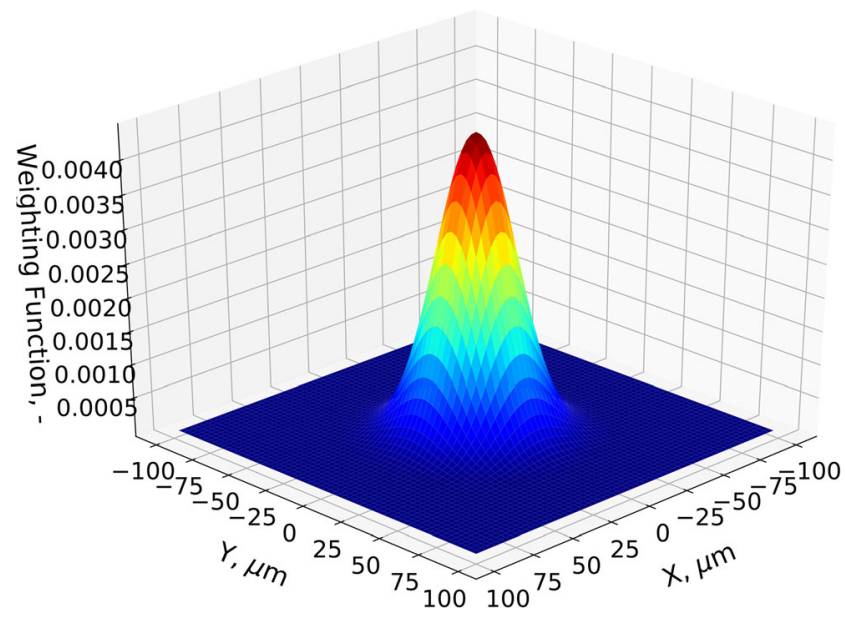

Fig. 2 Areal weighting function with $\lambda_{c}=100 \mu \mathrm{m}$ 
damage. The damage initiation criterion determined by the damage initiation locus (DIL) reads:

$\varepsilon^{i}=\left(c_{1}^{i} \cdot \exp \left(-c_{2}^{i} \cdot \eta\right)-c_{3}^{i} \cdot \exp \left(-c_{4}^{i} \cdot \eta\right)\right) \theta^{2}+c_{3}^{i} \cdot \exp \left(-c_{4}^{i} \cdot \eta\right)$

where $c_{1}^{i}, c_{2}^{i}, c_{3}^{i}$, and $c_{4}^{i}$ are DIL parameters that shall be calibrated. It is not only to determine the damage initiation as strain develops but also to identify the moment when the fracture occurs. As the damage evolution has once initiated, the damage evolution law is taken into account. It describes how the damage $D$ evolves while the strain increases by:

$D=\left\{\begin{array}{lr}0, & \varepsilon^{p} \leq \varepsilon^{i} \\ \frac{\sigma_{y, i}}{G_{f}} \varepsilon_{\varepsilon^{i}}^{\varepsilon^{p}} d \varepsilon^{p}, & \varepsilon^{i}<\varepsilon^{p}<\varepsilon^{f} \\ D_{c r}, & \varepsilon^{f} \leq \varepsilon^{p}\end{array}\right.$

where $\bar{\varepsilon}^{f}$ denotes the strain at the fracture point, $\sigma_{y, i}$ defines the yield stress at the damage initiation, $G_{f}$ is energy dissipation between the damage initiation and the fracture point of the material, and $D_{c r}$ is the critical value of the damage which defines the fracture point. More details on this material model can be found in [16]. In our numerical analysis, any local elements which yield this fracture point will be deleted from the analysis.

\section{Surface roughness model}

In order to characterize a state of a surface, the measured surface topology must be decomposed into two components, longwave and shortwave components. Longwave components of a surface profile can be simplified as smoothened surface profiles. For visualization purposes, a sample of 3D surface measurement data is illustrated in Fig. 1 (a). The raw surface is then filtered into waviness and roughness profiles as shown in Fig. 1 (b) and (c) respectively. One can notice that small peaks and outliers disappear from the waviness profile. On one hand, it can be argued that the waviness represents a flat line if the region of interest is downsized to an infinitesimal scale. On the other hand, the roughness represents surface
Table 1 Dimension of SRB tensile specimens of XAR450 steel, in mm

\begin{tabular}{ccccccc}
\hline $\mathrm{d}_{0}$ & $\mathrm{~L}_{0}$ & $\mathrm{~d}_{1}$ & $\mathrm{H}$ & $\mathrm{L}_{\mathrm{c}}$ & $\mathrm{L}_{\mathrm{t}}$ & $\mathrm{R}$ \\
\hline 8 & 40 & 12 & 10 & 48 & 75 & 4 \\
\hline
\end{tabular}

information on such a scale in which the inclination of the surface is removed.

To decompose these two components, the Gaussian filter is applied. Gaussian filter is a linear filter that is normally used in signal processing applications. It was introduced in profile analysis in 1992 [66] and later included as an official standard in 2011 [67]. In order to perform an areal surface filtration, a linear areal Gaussian filter shall be utilized. This requires a 2D convolution operation. It applies a mapping between the surface in the form of a 2D matrix and a weighting function $S$ (socalled kernel).

The main purpose of using such a filter is to extract waviness and roughness from the raw surface measurement data. Given $Z$ as the raw areal surface, the areal waviness $W$ and areal roughness $R$ can be calculated by:

$W=Z \otimes S$

$R=Z-W$

where $\otimes$ is the convolution operator.

The filter employs weighting function $S(x, y)$ and applies convolution using this kernel to the surface. The weighting function is given by [68]:

$S(x, y)=\frac{1}{\alpha^{2} \lambda_{c}^{2}} \exp \left[-\frac{\pi}{\alpha^{2}}\left(\frac{x^{2}+y^{2}}{\lambda_{c}^{2}}\right)\right]$

where $x, y$ are spatial location in $\mathrm{x}$ and $\mathrm{y}$ directions; $\lambda_{c}$ is a predefined cut-off wavelength; $\alpha$ is a constant equal to $\sqrt{\frac{\ln 2}{\pi}} \approx 0.4697$. The weighting function with $\lambda_{c}=100 \mu \mathrm{m}$ can be plotted as shown in Fig. 2.

After filtering the waviness out of the raw surface, the roughness from every measurement is accumulated and

Fig. 3 Geometric illustration of SRB specimens in tensile tests

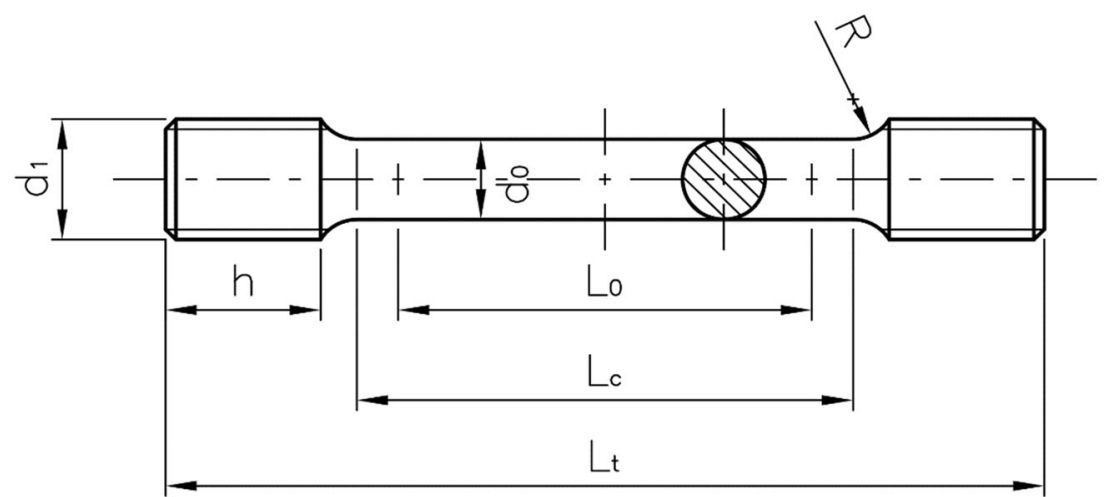


Fig. 4 Geometric illustration of SENB specimens

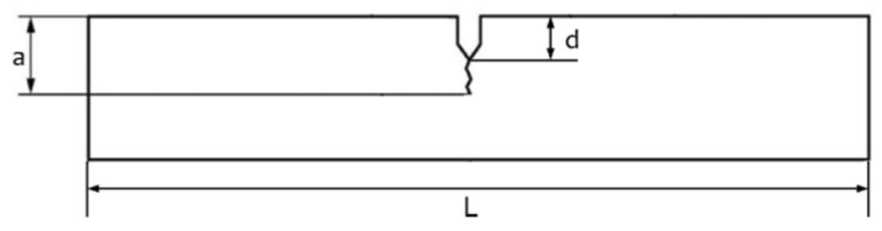

assumed to be distributed according to a normal distribution function, which reads:

$f\left(r \mid \mu_{r}, \sigma_{r}\right)=\frac{1}{\sqrt{2 \sigma_{r}^{2} \pi}} \exp \frac{\left(r-\mu_{r}\right)^{2}}{2 \sigma_{r}^{2}}$

where $\mu_{r}$ is the mean value of the distribution function; $\sigma_{r}$ is the standard deviation of the distribution function; $r$ is the depth of the roughness - a positive value means the measured surface is higher than the reference line and a negative value means vice versa.

\section{Material characterization}

The hybrid damage mechanics model consists of two parts, the description of the plastic flow behavior and the damage behavior. In this paper, the final application is bending process which yields its strain path at Lode angle parameter at $\bar{\theta}=0$. Therefore, the characterization can be done by experimental results from standard tensile tests and single-edge notched bending tests incorporating finite-element (FE) simulations. In addition, the surface condition of the material is also characterized by measurements from a white-light confocal microscope.

\section{Experiments}

\section{Tensile tests}

The steel grade XAR 450 (eXtra Abrasion Resistant) provided by ThyssenKrupp Steel Europe is taken into account. The tensile properties of the XAR 450 bulk material were measured by the smooth round bar (SRB) tensile tests. For the consideration of anisotropy, the SRBs were cut along two directions, rolling direction (L) and transverse direction (T). The SRB tests were performed at room temperature on a

Table 2 Geometry dimensions of SENB specimens

\begin{tabular}{llllrl}
\hline Name & L, mm & B, mm & W, mm & a, mm & d, mm \\
\hline a & 92 & 12 & 20 & 6.00 & 6 \\
b & 92 & 12 & 20 & 11.25 & 6 \\
c & 92 & 12 & 20 & 16.01 & 6 \\
\hline
\end{tabular}

Zwick Z100/TL3 machine. According to the European standard EN 6892-1 [69], specimens with geometry illustrated in Fig. 3 were prepared. The detailed dimensions are listed in Table 1. To achieve a quasi-static loading condition, the crosshead speed of $0.8 \mathrm{~mm} / \mathrm{min}$ was set, and the resulting strain rate for the uniaxial loading is approximately $3 \times 10^{-4} \mathrm{~s}^{-1}$.

\section{Single-edge notched bending (SENB) tests}

According to the damage model formulation, a series of fracture tests are required to characterize the damage curve of the XAR 450. The geometrical features of the SENB specimens are illustrated in Fig. 4. All specimens have a length of $92 \mathrm{~mm}$, a width of $10 \mathrm{~mm}$ and a height of $20 \mathrm{~mm}$. One of the important characteristics in the design of SENB specimens is the depth of the pre-crack. The target for the design is to cover a broad range of stress states. The first crack that appears in SENB specimens is located beneath the pre-crack or notch (when no pre-crack is assigned) in the mid-plane of the thickness direction. The stress state at this location features a Lode angle parameter in the vicinity of zero and its value is influenced by the implementation of side grooves. The stress triaxiality of the same location is varied by the existence of pre-cracks. Therefore, there are three different types of specimens investigated, according to the possible changes of the depth of the pre-crack. The corresponding measured dimensions after the manufacture of these samples are listed in Table 2.

The SENB tests were performed at room temperature at a constant piston velocity of $0.4 \mathrm{~mm} / \mathrm{min}$ in a Schenck servo-

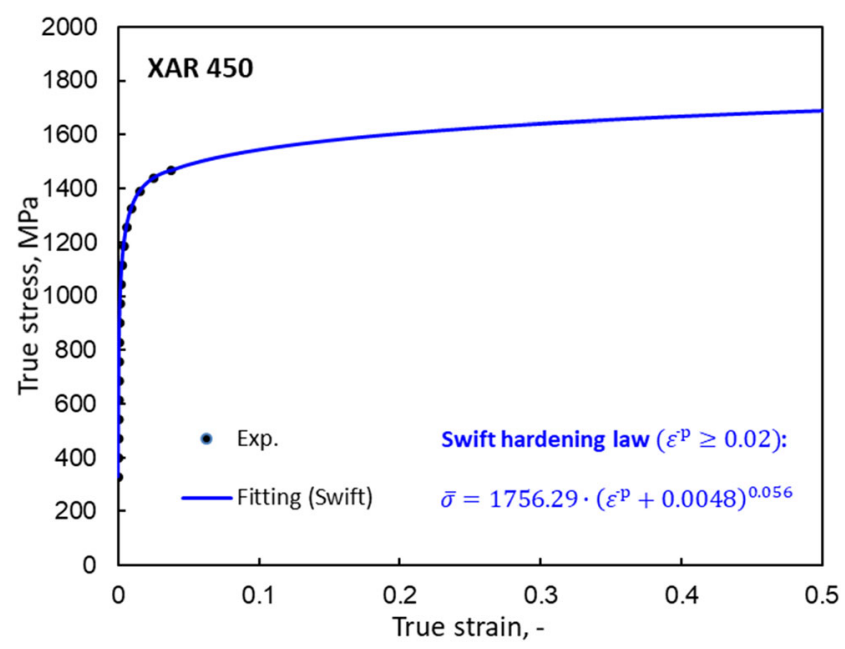

Fig. 5 Calibrated XAR 450 flow curve 
Table 3 Calibrated XAR 450 hardening parameters for equivalent plastic strain larger than 0.02

\begin{tabular}{lll}
\hline$A,-$ & $n,-$ & $\bar{\varepsilon}_{0},-$ \\
\hline 1756.29 & 0.056 & 0.0048 \\
\hline
\end{tabular}

hydraulic testing machine with a maximum force of $400 \mathrm{kN}$. During the tests, the applied force was measured with a load cell. Furthermore, the crack tip opening displacement (CTOD) was determined with clip gages. The experimental device for carrying out the SENB test consists of two rollers at a distance of $80 \mathrm{~mm}$, serving as supports on the top side of the specimen. The third roller embedded in a piston presses the specimen in the middle from the bottom side. The two support bearings have the same diameter of $10 \mathrm{~mm}$, while the third roller fixed to the piston has a diameter of $5 \mathrm{~mm}$. All tests were performed until the specimens were totally fractured. The instant of damage initiation is detected by the direct current potential drop method [70].

\section{Parameter calibration}

\section{Plastic flow behavior}

The engineering stress-strain curve from tensile test results in the rolling direction is converted to the true stress-strain curve. In order to provide a sufficient range of the flow curve to the finite element analysis (FEA) software for the damage behavior study, the converted true stress-strain curve is extrapolated according to the Swift hardening law.

$\bar{\sigma}=A \cdot\left(\frac{p}{\bar{\varepsilon}}+\bar{\varepsilon}_{0}\right)^{n}$

where $\bar{\sigma}$ is extrapolated equivalent stress; $\bar{\varepsilon}_{0}$ is yield strain; $A$ and $n$ are parameters to be identified from experimental results. The true stress-strain results are fitted according to (14) and both the experimental flow curve and the fitted one are presented in Fig. 5. It is noted that due to the steep initial hardening of the material, the stress-strain curve cannot be fitted with one Swift equation for good quality. Therefore, a piece-wise hardening description is adopted in this study. For equivalent plastic strain lower than 0.02 , the experimental data is used, while for larger strains, the Swift equations is fitted and used to describe the hardening behaver. The corresponding material parameters are listed in Table 3.

Table 4 Calibrated XAR 450 DIL parameters

\begin{tabular}{lc}
\hline$c_{3}^{i},-$ & $c_{4}^{i},-$ \\
\hline 2.855 & 1.949 \\
\hline
\end{tabular}

\section{Damage behavior}

This part requires a combination of SENB experimental results and its FE simulations. The simulation settings follow the FE model reported in a previous study [16]. The elements are the type of 3D continuum elements with reduced integration (C3D8R). The region around the ligament under the notch tip is meshed with a fine size of $0.1 \mathrm{~mm} \times 0.1 \mathrm{~mm} \times 0.1 \mathrm{~mm}$, as it features the most plastic deformation, while the remaining part of the specimen has significantly coarser enmeshment to improve the computational efficiency. The support bearings and the punch are modeled as rigid solids, and a Coulomb friction value of 0.1 is assumed to consider the contact phenomena between sample and rollers. According to the experiment, two supporting rollers on the top are fixed in all degrees of freedom, while the bottom roller is lifted up with a constant velocity to bend the specimen until it is fractured.

The hybrid damage mechanics model describes the damage initiation by the equivalent plastic strain with a weight function of stress triaxiality and Lode angle parameter. The DIL is constructed by experimental results from SENB tests at different pre-crack depths. As mentioned earlier, the final application's Lode angle parameter along the strain path is zero, the DIL in (8) can be simplified to:

$\varepsilon^{i}=c_{3}^{i} \cdot \exp \left(-c_{4}^{i} \cdot \eta\right)$

FE simulations are employed to calculate the local stress triaxiality $\eta$ at the critical element at the instant of fracture. These values are then included in the calculation and calibrate the DIL parameter which is listed in Table 4.

\section{Surface roughness measurement}

There are two samples delivered for roughness analysis, SP1 and SP2. Both samples are simple rectangular steel plates with a difference in width. The surface roughness for both specimens was measured by NanoFocus confocal microscope using 10x magnitude, lens aperture (f-value) 0.3 , shutter speed $1 / 100 \mathrm{~s}$, ISO 100 . This setting allows us to achieve $3.125 \mu \mathrm{m}$ on-plane resolution and $20 \mathrm{~nm}$ out-of-plane resolution. The total number of measurement regions is 40 . Each measurement covers $4.2 \mathrm{~mm}$ by $4.2 \mathrm{~mm}$ area. The noise from measurement is filtered by a robust Gaussian regression filter [71] with a cut-off wavelength of $3.125 \mu \mathrm{m}$ to eliminate some artifacts whose wavelength is lower than the machine's resolution. The filtered surface is then decomposed into waviness and roughness component using Gaussian filter with $\lambda_{c}=$ $100 \mu \mathrm{m}$. This number is chosen to match the element size in the critical region and the sub-model size.

Before merging the surface information, all surfaces are shifted to obtain zero mean value. Thus, all points lie on an identical reference plane. Afterwards, a regression is 


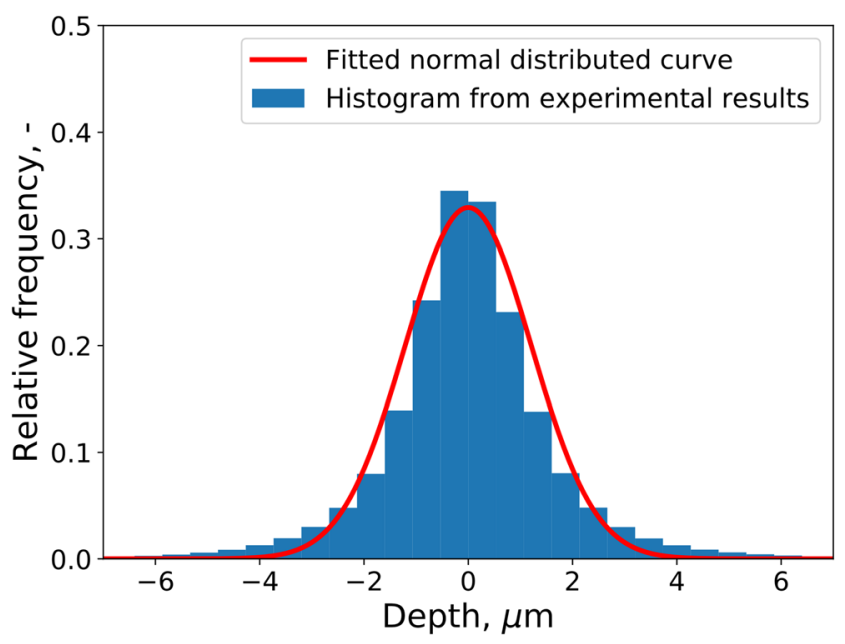

Fig. 6 Histogram of the measured roughness and fitted distribution function with $\mu_{r}=0, \sigma_{r}=1.83$

performed to find the overall standard deviation $\sigma_{r}$. The distribution function corresponding to these parameters are plotted along with a roughness histogram in Fig. 6.

\section{Plate bending process}

A three-point bending test is a standard test for the characterization of bendability. For the heavy plate application, it is also often used as an experimental technique to assess the cold formability of steels for the manufacturing of components with extensive cold forming involved. In the experimental set-up of bending tests, a steel plate of defined size is subjected to a symmetric three-point bending treatment. The distance between the two support bearings is a function of the plate thickness and the radius of the cylindrical punch which applies the load, so that the whole geometrical set-up of the test is defined by the punch radius $r$ and the sample thickness $t$.
Table 5 Geometrical details for all six simulations of bending tests

\begin{tabular}{lcc}
\hline$r / t,-$ & Support distance, $\mathrm{mm}$ & Punch displacement, mm \\
\hline 0.2 & 42 & 60.20 \\
1.0 & 66 & 67.22 \\
1.5 & 81 & 71.61 \\
3.0 & 126 & 73.00 \\
4.0 & 156 & 78.00 \\
4.5 & 171 & 93.00 \\
5.0 & 186 & 102.40 \\
7.0 & 246 & 120.00 \\
\hline
\end{tabular}

The working cycle of the bending test is illustrated in Fig. 7: (a) the plate is placed according to a given $r / t$ ratio; (b) the punch moves from top to the bottom to deform the plate into a certain extent when the plate is bent at approximately $90^{\circ}$ in the middle; (c) the punch goes back to the initial place and allows the plate to release its elastic deformation. After one cycle, the plate is removed, and the system starts with another working cycle. In this way, a series of tests are performed, in which the dimension of the plate is constant, but the $r / t$ ratio is defined as a variable by varying the punch radius. Accordingly, the distance between two barriers, $3 t+2 r$ is changed for each test. The investigation is aiming to find the critical $r / t$ ratio to trigger crack/damage initiation on the plate.

\section{FE model}

The investigations were performed on samples with a length of $400 \mathrm{~mm}$, a width of $150 \mathrm{~mm}$ and a thickness of $12 \mathrm{~mm}$. The $r / t$ ratios are chosen as $0.2,1.0,1.5,3.0,4.0,4.5,5.0$ and 7.0. The selection of these $r / t$ ratios was based on the available punch radii of the laboratory where the experiments were conducted. Before the simulations were carried out, the load line displacement of the punch required to bend the sample to an angle of $90^{\circ}$ was calculated analytically. Likewise, the simulations could be performed such that the required punch displacement is applied, and the punch

Fig. 7 Operating cycle of the cold forming test: (a) Setup of the test with a given $r / t$ ratio; (b) Bending deformation of the plate to approximately $90^{\circ}$ by the movement of the punch; (c) Unloading by moving the punch to its initial place to allow the plate to release the elastic deformation [16]

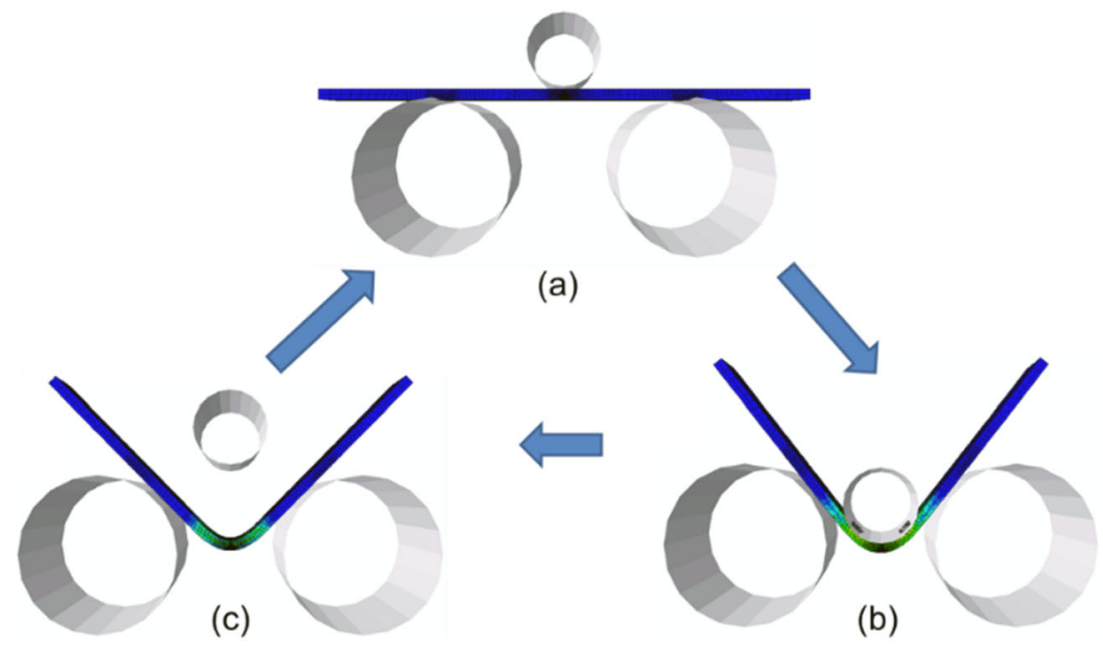


Fig. 8 Geometrical setup of the bending tests with six different $r / t$ ratios

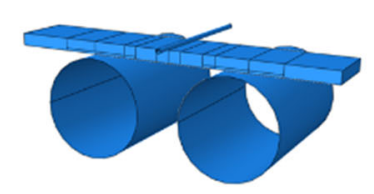

$r / t=0.2$

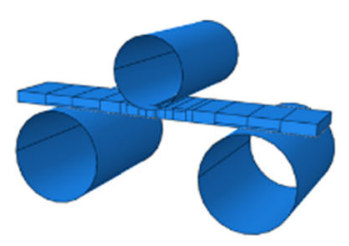

$r / t=3.0$

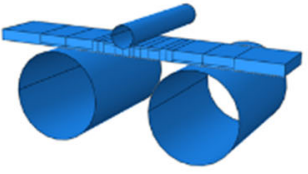

$r / t=1.0$

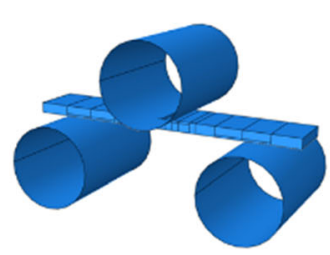

$r / t=4.0$

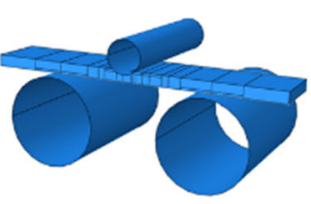

$r / t=1.5$

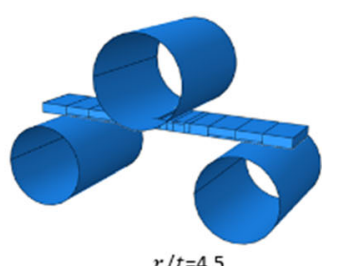

$r / t=4.5$

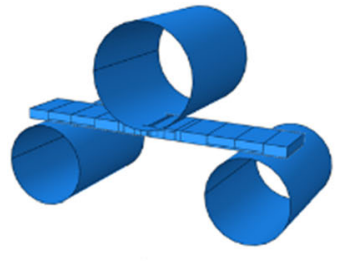

$r / t=5.0$

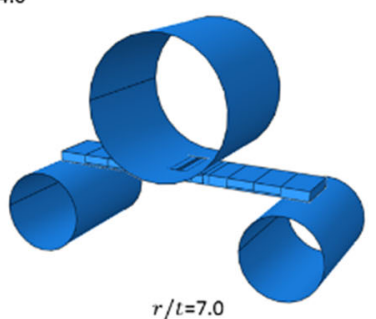

moves back to its original position. All the geometrical details required to perform the simulations are summarized in Table 5, and Fig. 8 shows the geometrical set-up considered in the simulations.

Due to the simplification of the material property of the three pins, the boundary condition is constrained to a single reference point. All the boundary conditions lie in the category of displacement restriction. Simply the two barriers above are restricted in all directions to move, whereas the hammer on the top is fixed in both $\mathrm{x}$ and $\mathrm{z}$ directions, but movable in the $\mathrm{y}$ direction to deform the plate. The specific displacement is calculated to meet the requirement that after the hammer is back to the initial place, the plate remains bent at approximately $90^{\circ}$. For the plate, according to the symmetrical boundary condition, the corresponding plane is restricted to move in the symmetrical direction, which is the z-direction in this case. At the zones of contiguity among the pins and plate, the surface- to-surface contact interactions are applied with the consideration of friction. The friction coefficient is assumed to be 0.1 .

\section{Scale bridging approach}

In order to analyze roughness features, a multiscale modeling scheme is defined. The overview of the scheme is depicted in Fig. 9. It starts from an analysis at the component level, the plate bending test in this context. The bending test simulation is conducted in the configuration without any consideration of the roughness profile. The mesh size for such simulations is typically $100 \mu \mathrm{m}$. With these simulations, the local loading history for the critical element is achieved. Accordingly, the same loading condition is then applied to a smaller level, namely meso-level, in which a single element from the macro-level is further discretized for finer resolution and the roughness profile is also statistically included for simulations

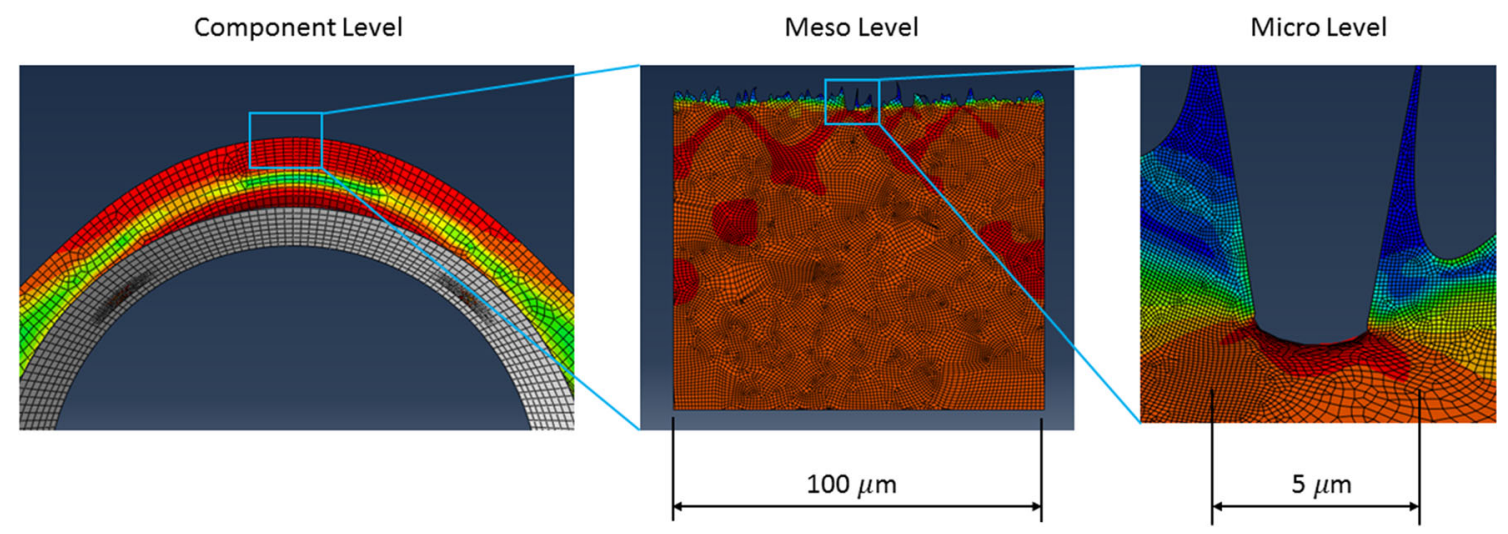

Fig. 9 Multiscale modeling strategy for roughness features 
Fig. 10 Schematic illustration for the representation of roughness in RVE model

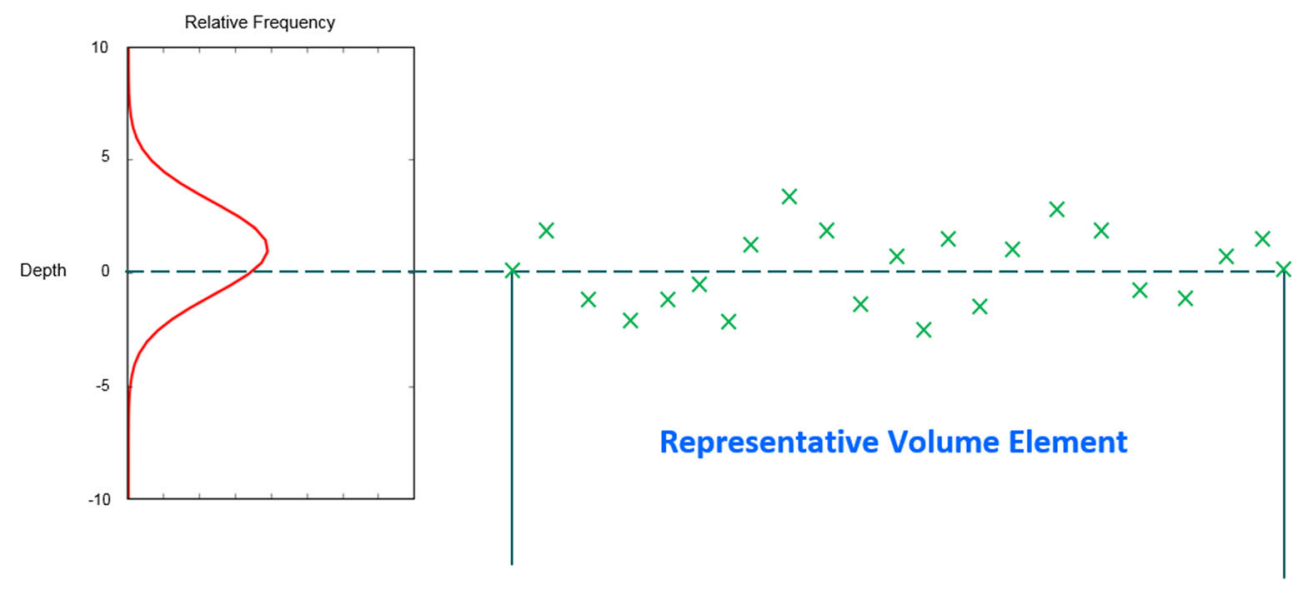

via the creation of the sub-model. Naturally, a $100 \mu \mathrm{m} \times 100$ $\mu \mathrm{m}$ sub-model with roughness features located at critical region of the component is considered corresponding to the macro-scale models. The element size in the representative volume element (RVE) is sub-micrometer, $0.6 \mu \mathrm{m}$ in particular, for a proper representation of the roughness profile; however, the damage initiation is not rendered in such a tiny length scale. Therefore, the evaluation of damage initiation is not performed on the single element of the RVE model in the meso-level. Consequently, a third level, micro-level is introduced. This level features a size of $5 \mu \mathrm{m}$, which physically corresponds the minimum damage initiation length from the DCPD method $[2,11]$. The homogenized local values, such as equivalent plastic strain and stress triaxiality, within in this level size are considered as the local results for damage initiation analysis incorporating with the roughness profile, while the homogenized values over the whole sub-model in the meso-scale are considered as the average result, which can be interpreted in the macro level for the $r / t$ ratio analysis.

\section{Sub-model generation}

The meso-scale and the micro-scale model require an unconventional sub-model generation. The top surface of the submodel contains the specimen's surface information. This information is characterized by plate roughness measurement. The obtained distribution function represents the material's surface condition despite their difference in measured locations. Figure 10 illustrates how to generate a roughness feature onto the sub-model. The dashed line indicates the original flat surface of the sub-model. Points are randomly placed according to the corresponding distribution function. Subsequently, those points are connected by second-order polynomial lines.

Fig. 11 Sub-model with roughness profile

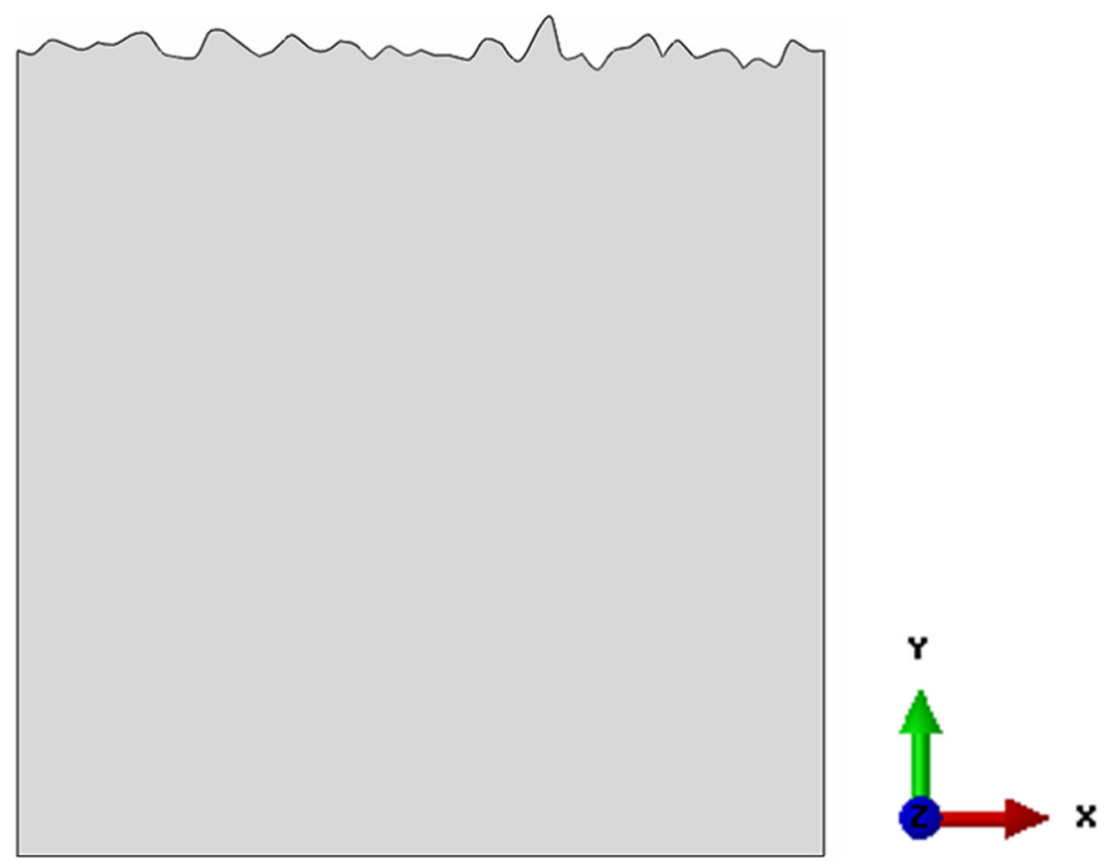


Fig. 12 Probability of crack-free bending for different $r / t$ ratio from experiments and the crack-free bending boundary evaluated from the experimental results

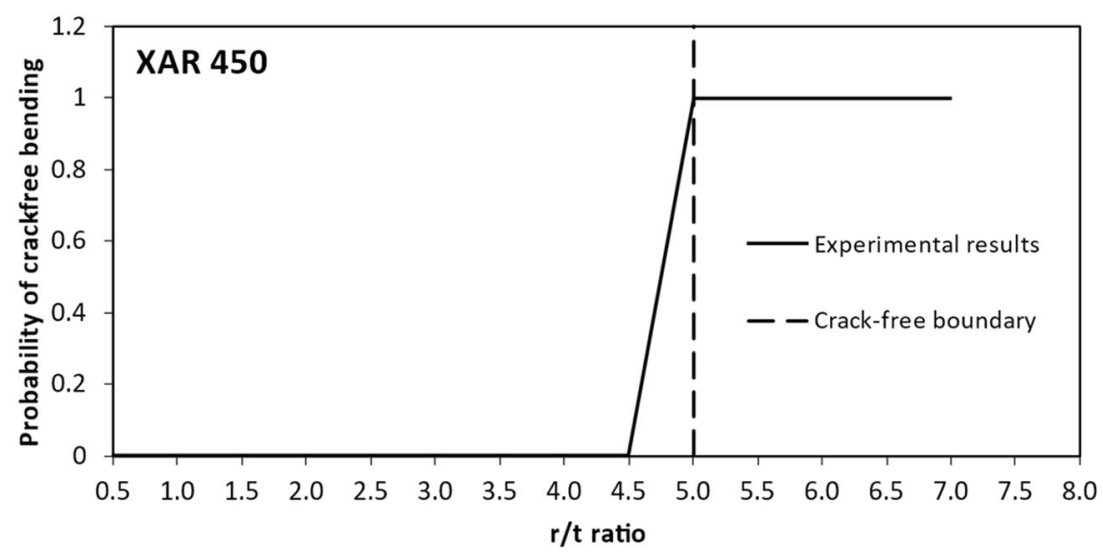

Sub-models with roughness characteristics identified experimentally are generated in the FE software ABAQUS/CAE 6.14, as shown in Fig. 11. The sub-model generation platform also distinguishes the grains for the microstructure. However, this work treats these grains homogeneously by the $\mathrm{J} 2$ plasticity material model. Symmetrical boundary conditions at the left and bottom side as well as $10 \mu \mathrm{m}$ displacement $(10 \%)$ in $+x$ direction at the right-hand side are applied. Local results with the length scale of $5 \mu \mathrm{m}$ and average results are extracted from the simulation. The triaxiality $\eta$, Lode angle parameter $\bar{\theta}$ and equivalent plastic strain $\bar{\varepsilon}^{\mathrm{p}}$ are calculated from these results.

\section{Results}

\section{Plate bending experiments}

It can be expected that the plate bending tests with smaller $r / t$ ratios are more likely for cracks to be detected after the process. However, to obtain the best shape of the final structure, a smaller radius tool is more appreciated. The experimental results performed by the Heavy Plate Unit of Thyssen Krupp
Steel Europe AG are summarized in Fig. 12. It illustrates the application boundary which yields the smallest $r / t$ ratio without crack observed after bending. If the application is applied on the right-hand side of this boundary, it is ensured that the process is crack-free. On the other hand, if the $r / t$ ratio exceeds the boundary to the left-hand side, it is likely to observe cracks after the bending process.

\section{Cold-formability prediction}

\section{Prediction without considering surface roughness}

The cold formability is evaluated from the plate bending simulation in which $r / t$ ratios are varied. The values $0.2,1.0,1.5$, 3.0, 4.0, 4.5, 5.0 and 7.0 are selected. Their response curves are illustrated in Fig. 13. The point at the end of each line indicates the end of the process when the plate is bent to a $90^{\circ}$ angle after unloading. It is clear that only the loading paths of $r / t$ ratio 0.2 and 1.0 intersect with the DIL derived from the SENB tests, which means under these two $r / t$ ratios, the plate will encounter damage during the bending process. All the rest $r / t$ ratios will be safe for the bending process. One can notice that the smaller $r / t$ ratio is more likely to trigger damage.
Fig. 13 Response curve of plate bending test simulation at different $r / t$ ratio comparing to DIL of XAR 450

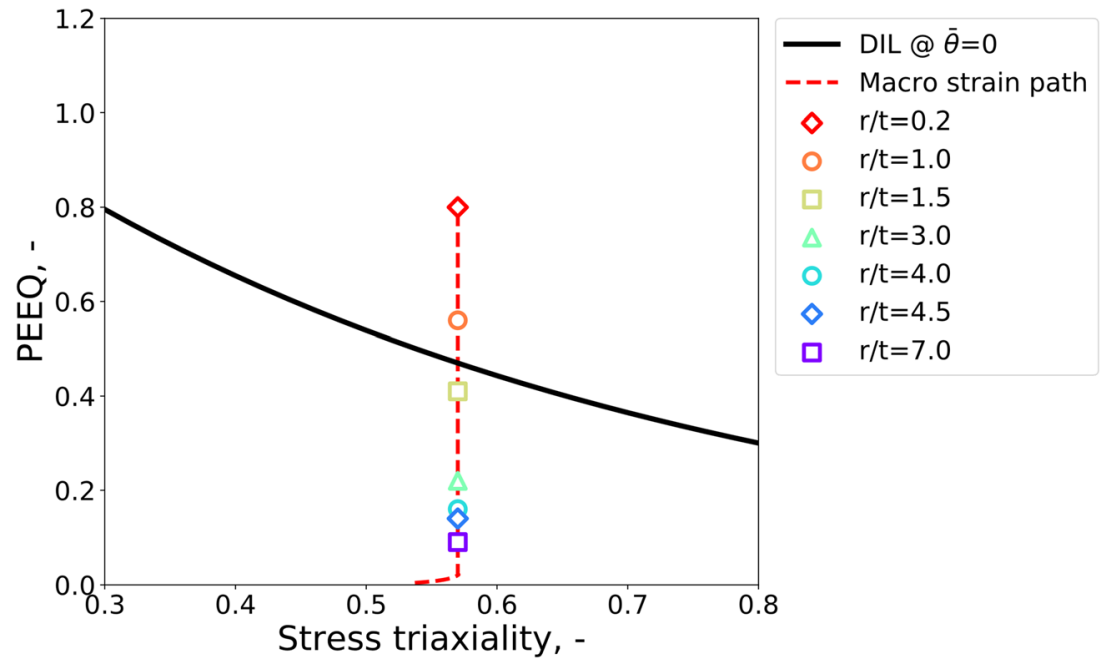


Fig. 14 Plate bending prediction with smooth surface comparing to the crack-free boundary from the experimental results
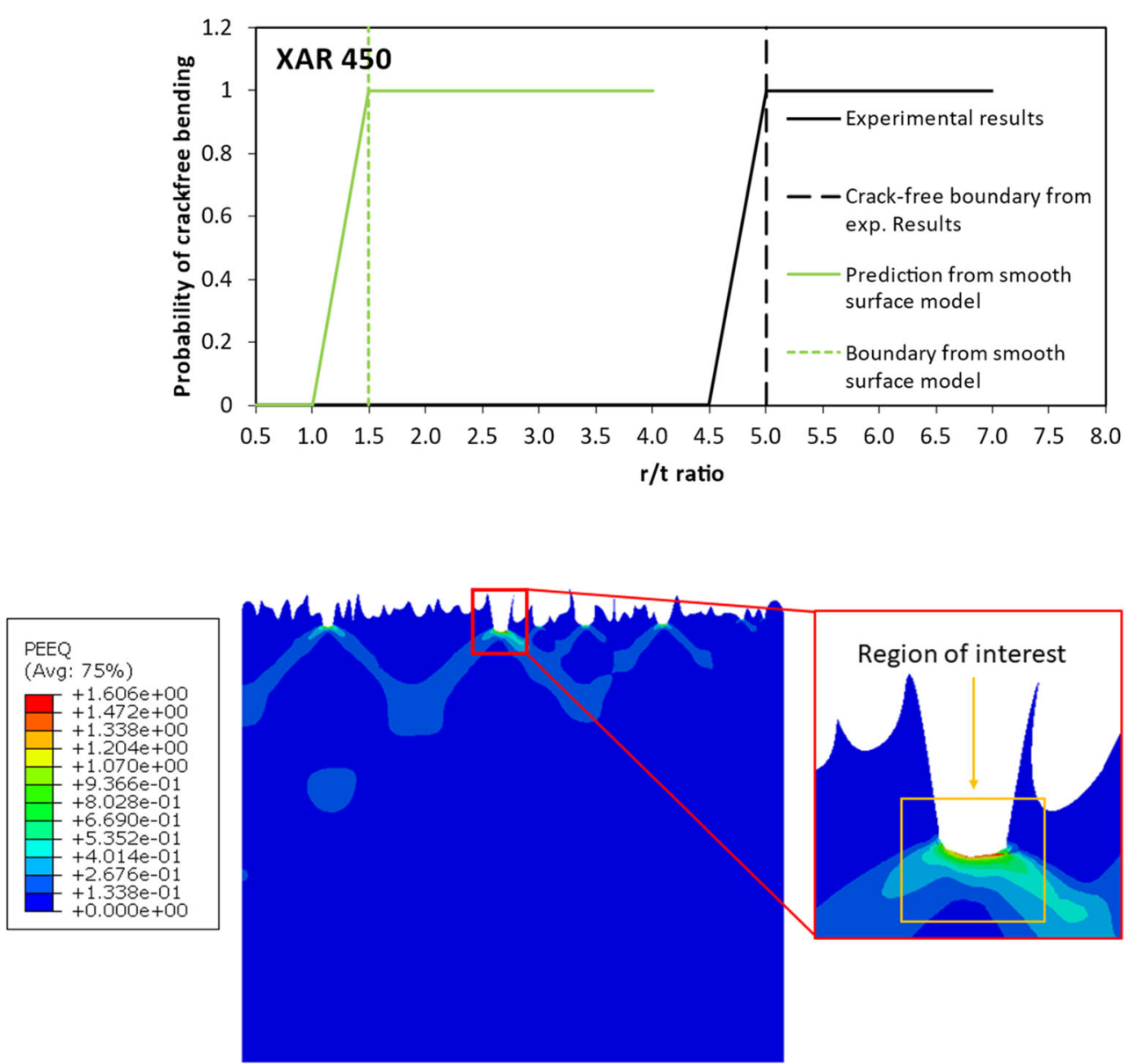

Fig. 15 Deformed sub-model for the local evaluation of damage initiation
Figure 14 compares the prediction with the boundary obtained from the experiments. It is obvious that the model suggests that the process is safe to perform until $r / t=1.5$. This conclusion deviates from the experimental discovery in quite a large extent. Therefore, the model with roughness included shall be investigated.

\section{Prediction considering roughness profiles}

Once roughness is included in the sub-model, the localization shall be taken into account. This analysis applies a $5 \times 5 \mu \mathrm{m}$ rectangle as the region of interest to identify the localization as shown in Fig. 15. The local stress triaxiality and equivalent
Fig. 16 The response curve of plate bending test simulation at different $r / t$ ratio and local strain path of the sub-models comparing to DIL of XAR 450

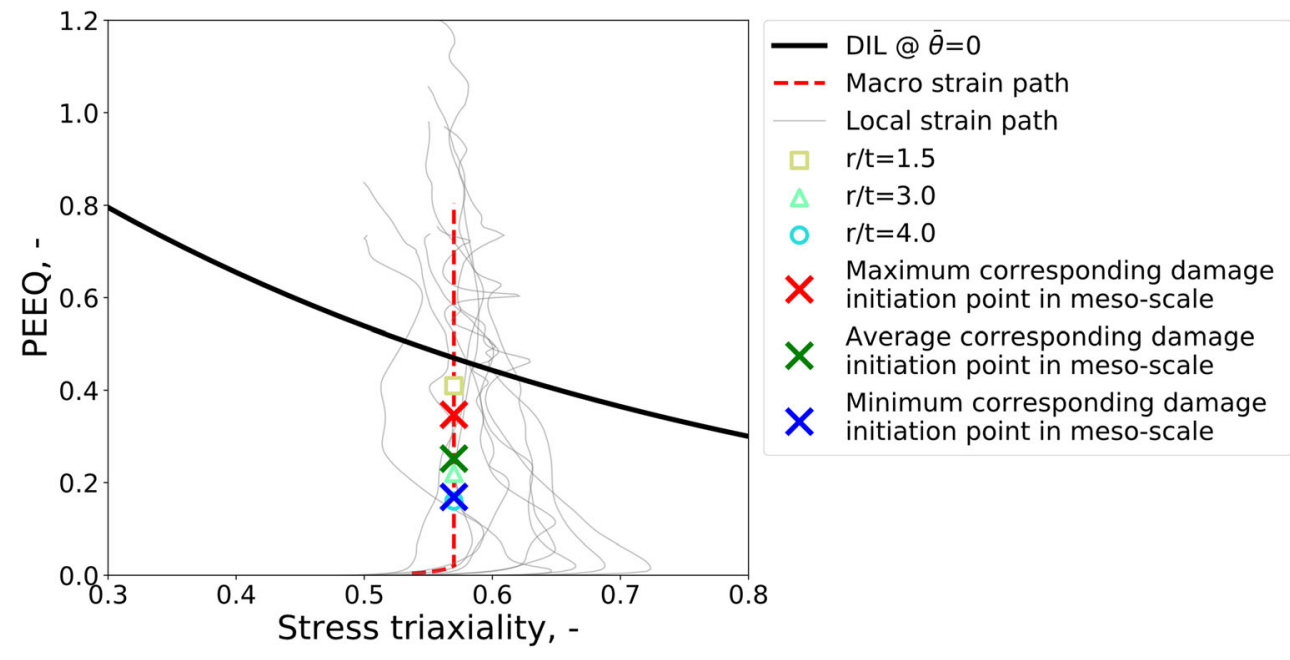


Fig. 17 Plate bending prediction with a smooth surface and rough surface compared to the crackfree boundary from the experimental result

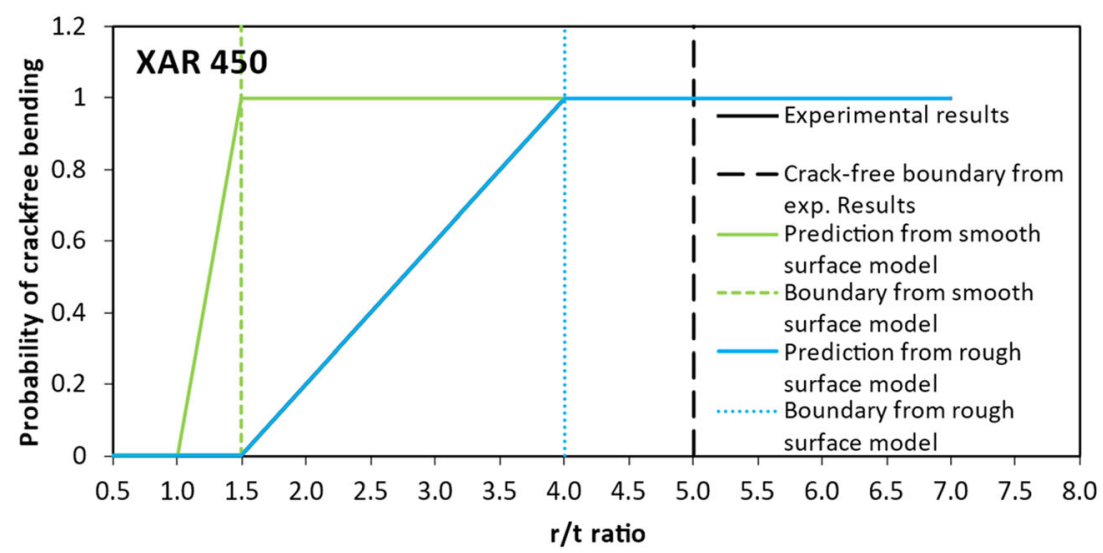

plastic strain are calculated and averaged inside this region. Simultaneously, the local variables over the whole $100 \times 100$ $\mu \mathrm{m}$ sub-model are calculated to represent the response in the meso-scale.

As the loading is applied to the sub-model, the plate is considered to fracture upon the time step in which the local strain path exceeds the DIL. This time step is linked to the mesoscale response and compared to the macro strain path. Due to the random function that generates the roughness feature of the sub-model, multiple sub-models with a constant standard deviation are generated and simulated. Figure 16 illustrates local strain paths comparing to strain path from the macroscopic simulation. The results indicate possibilities that the plate will fracture at the PEEQ between 0.252 and 0.169 . In other words, the simulations with surface roughness predict that the bending plate will definitely see the crack at the $r / t$ ratio lower than 1.5 and it will be crack-free bending as long as the $r / t$ ratio is higher than 4.0. The crack-free boundary is considered from the most severe surface, which yields the minimum corresponding damage initiation point in the meso-scale. The prediction curve in Fig. 17 indicates that the roughness features allows us to predict the crack-free boundary closer to the experimental result than the smooth surface model. It is obvious from the analysis that the stress localization due to the structure surface geometry, and therefore the surface condition plays a role in triggering the onset of damage during loading.

\section{Conclusions}

- In this paper, we have proposed a novel multi-scale simulation strategy that considers the effect of surface rougthness in the plate bendability prediction. The approach links the macroscopic bending test with the micro-roughness profile by sub-models, in which the measured roughness profile was statistically represented. Via proper definition of the length scales of different levels and the homogenization method, the approach, on the one hand, renders the physical "local-level" damage behavior under the presence of roughens profile and on the other hand links the result to a "meso-level" for the analysis of the critical $r / t$ ratio.

- Evaluating the simulation results, the critical $r / t$ ratio lies between 1.0 and 1.5 when the roughness profile was not considered in the analysis. Considering the roughness profile via the multiscale modeling scheme, the critical $r / t$ ratio falls between 1.5 and 4.0 when the local material point reached the damage initiation. In other words, instead of predicting the $r / t$ ratio of 1.5 as safe, it predicts a safe $r / t$ ratio at 4.0. This result yields a better prediction despite some deviations.

- It is concluded that the roughness profile plays a significant role in the cold formability/bendability prediction in plate bending tests. The roughness of the surface reduces the cold formability/bendability to a large extent compared with the results of an ideal smooth surface condition. The reason for this degradation of the mechanical property is related to the severe local strain localization included by the geometrical inhomogeneity of the surface roughness profile, which ultimately triggers an early local damage initiation on the surface.

Funding information Open access funding provided by Aalto University. This project is supported by Thyssen Krupp Steel AG.

\section{Compliance with ethical standards}

Conflict of interest The authors declare that they have no conflict of interest.

Open Access This article is licensed under a Creative Commons Attribution 4.0 International License, which permits use, sharing, adaptation, distribution and reproduction in any medium or format, as long as you give appropriate credit to the original author(s) and the source, provide a link to the Creative Commons licence, and indicate if changes were made. The images or other third party material in this article are included in the article's Creative Commons licence, unless indicated otherwise in a credit line to the material. If material is not included in the article's Creative Commons licence and your intended use is not permitted by statutory regulation or exceeds the permitted use, you will need to obtain 
permission directly from the copyright holder. To view a copy of this licence, visit http://creativecommons.org/licenses/by/4.0/.

\section{References}

1. Grässel O, Krüger L, Frommeyer G, Meyer LW (2000) High strength Fe-Mn-(Al, Si) TRIP/TWIP steels development - properties - application. Int J Plast 16(10-11). https://doi.org/10.1016/ S0749-6419(00)00015-2

2. Münstermann S, Lian J, Bleck W (2012) Design of damage tolerance in high-strength steels. Int J mater res 103(6):755-764. https:// doi.org/10.3139/146.110697

3. Deng, G, Nagamoto, K, Nakano, Y, Nakanishi T (2009). Evaluation of the effect of surface roughness on crack initiation life. In: ICF12, Ottawa

4. Javidi A, Rieger U, Eichlseder W (2008) The effect of machining on the surface integrity and fatigue life. Int J Fatigue 30:10-11. https://doi.org/10.1016/j.jfatigue.2008.01.005

5. Xie HB, Jiang ZY, Yuen WYD (2011) Analysis of friction and surface roughness effects on edge crack evolution of thin strip during cold rolling. Tribol Int 44(9). https://doi.org/10.1016/j.triboint.2011.03.029

6. Xie Q, Li R, Wang YD, Su R, Lian J, Ren Y, Zheng W, Zhou X, Wang Y (2018) The in-depth residual strain heterogeneities due to an indentation and a laser shock peening for Ti-6Al-4V titanium alloy. Mater Sci Eng A 714:140-145. https://doi.org/10.1016/j. msea.2017.12.073

7. As S, Skallerud B, Tveiten B (2008) Surface roughness characterization for fatigue life predictions using finite element analysis. Int J Fatigue 30(12):2200-2209. https://doi.org/10.1016/j.ijfatigue.2008.05.020

8. Lai J, Huang H, Buising W (2016) Effects of microstructure and surface roughness on the fatigue strength of high strength steels. Procedia Structural Integrity 2:1213-1220. https://doi.org/10.1016/ j.prostr.2016.06.155

9. McKelvey SA, Fatemi A (2012) Surface finish effect on fatigue behavior of forged steel. Int J Fatigue 36(1). https://doi.org/10. 1016/j.ijfatigue.2011.08.008

10. Gu C, Wang M, Bao YP, Wang FM, Lian JH (2019) Quantitative analysis of inclusion engineering on the fatigue property improvement of bearing steel. Metals 9(4):15. https://doi.org/10.3390/met9040476

11. Lian J, Yang H, Vajragupta N, Münstermann S, Bleck W (2014) A method to quantitatively upscale the damage initiation of dualphase steels under various stress states from microscale to macroscale. Comput mater Sci 94:245-257. https://doi.org/10.1016/j. commatsci.2014.05.051

12. Wu B, Vajragupta N, Lian J, Hangen U, Wechsuwanrnanee P, Muenstermann S (2017) Prediction of plasticity and damage initiation behaviour of $\mathrm{C} 45 \mathrm{E}+\mathrm{N}$ steel by micromechanical modelling. Mater Des 121:154-166. https://doi.org/10.1016/j.matdes.2017.02.032

13. Liu W, Lian J, Aravas N, Münstermann S (2020) A strategy for synthetic microstructure generation and crystal plasticity parameter calibration of fine-grain-structured dual-phase steel. Int J Plast 126: 102614. https://doi.org/10.1016/j.ijplas.2019.10.002

14. Xie Q, Lian J, Sidor JJ, Sun F, Yan X, Chen C, Liu T, Chen W, Yang P, An K, Wang Y (2020) Crystallographic orientation and spatially resolved damage in a dispersion-hardened $\mathrm{Al}$ alloy. Acta Mater 193:138-150. https://doi.org/10.1016/j.actamat.2020.03.049

15. Lian J, Sharaf M, Archie F, Münstermann S (2013) A hybrid approach for modelling of plasticity and failure behaviour of advanced high-strength steel sheets. Int J Damage Mech 22(2):188-218. https://doi.org/10.1177/1056789512439319

16. Lian J, Wu J, Muenstermann S (2015) Evaluation of the cold formability of high-strength low-alloy steel plates with the modified BaiWierzbicki damage model. Int J Damage Mech 24(3):383-417. https://doi.org/10.1177/1056789514537587
17. Benzerga AA, Leblond JB (2010). Ductile fracture by void growth to coalescence. Adv Appl Mech https://doi.org/10.1016/S00652156(10)44003-X

18. Benzerga AA, Leblond J-B, Needleman A, Tvergaard V (2016) Ductile failure modeling. Int J Fract 201(1):29-80. https://doi.org/ 10.1007/s10704-016-0142-6

19. Pineau A, Benzerga AA, Pardoen T (2016) Failure of metals I: brittle and ductile fracture. Acta Mater 107:424-483. https://doi. org/10.1016/j.actamat.2015.12.034

20. Bao YB, Wierzbicki T (2004) On fracture locus in the equivalent strain and stress triaxiality space. Int J Mech Sci 46(1):81-98. https://doi.org/10.1016/j.ijmecsci.2004.02.006

21. Besson J (2009) Continuum models of ductile fracture: a review. Int J Damage Mech 19(1):3-52. https://doi.org/10.1177/ 1056789509103482

22. Clift SE, Hartley P, Sturgess CEN, Rowe GW (1990). Fracture prediction in plastic deformation processes. Int J Mech Sci https:// doi.org/10.1016/0020-7403(90)90148-C, 32, 1

23. Cockcroft MG, Latham DJ (1968) Ductility and the workability of metals. J Inst Met 96:33-39

24. Ebnoether F, Mohr D (2013) Predicting ductile fracture of low carbon steel sheets: stress-based versus mixed stress/strain-based Mohr-coulomb model. Int J solids Struct 50(7-8):1055-1066. https://doi.org/10.1016/j.ijsolstr.2012.11.026

25. Kailasam M, Castaneda PP (1998) A general constitutive theory for linear and nonlinear particulate media with microstructure evolution. J Mech Phys Solids 46(3):427-465

26. Oh SI, Chen CC, Kobayashi S (1979) Ductile Fracture in Axisymmetric Extrusion and Drawing .2. Workability in Extrusion and Drawing. J Eng Ind Trans ASME 101(1):36-44

27. Lemaitre J (1985) A continuous damage mechanics model for ductile fracture. J Eng Mater Technol-Trans ASME 107(1):83-89

28. Johnson GR, Cook WH (1985) Fracture characteristics of 3 metals subjected to various strains, strain rates, temperatures and pressures. Eng Fract Mech 21(1):31-48

29. Lou Y, Huh H, Lim S, Pack K (2012) New ductile fracture criterion for prediction of fracture forming limit diagrams of sheet metals. Int J Solids Struct 49(25):3605-3615

30. McClintock FA (1968) A criterion for ductile fracture by growth of holes. J Appl Mech 35(2):363-371. https://doi.org/10.1115/1. 3601204

31. Mohr D, Marcadet SJ (2015) Micromechanically-motivated phenomenological Hosford-coulomb model for predicting ductile fracture initiation at low stress triaxialities. Int J Solids Struct 67-68:40 55. https://doi.org/10.1016/j.ijsolstr.2015.02.024

32. Oyane M, Sato T, Okimoto K, Shima S (1980) Criteria for ductile fracture and their applications. J Mech Work Technol 4(1). https:// doi.org/10.1016/0378-3804(80)90006-6

33. Rice JR, Tracey DM (1969) On ductile enlargement of voids in triaxial stress fields. J Mech Phys Solids 17(3):201-217

34. Zhang ZL, Thaulow C, Ødegård J (2000) Complete Gurson model approach for ductile fracture. Eng Fract Mech 67(2). https://doi.org/ 10.1016/S0013-7944(00)00055-2

35. Cao TS, Bobadilla C, Montmitonnet P, Bouchard PO (2015) A comparative study of three ductile damage approaches for fracture prediction in cold forming processes. J Mater Process Technol 216: 385-404. https://doi.org/10.1016/j.jmatprotec.2014.10.009

36. Gurson AL (1977) Continuum theory of ductile rupture by void nucleation and growth: part I-yield criteria and flow rules for porous ductile media. J Eng Mater Technol-Trans ASME 99(1):2-15

37. Khan AS, Liu HW (2012) A new approach for ductile fracture prediction on Al 2024-T351 alloy. Int J Plast 35:1-12

38. Cao TS, Mazière M, Danas K, Besson J (2015) A model for ductile damage prediction at low stress triaxialities incorporating void shape change and void rotation. Int J Solids Struct 63. https://doi. org/10.1016/j.ijsolstr.2015.03.003 
39. Pardoen T (2006) Numerical simulation of low stress triaxiality ductile fracture. Comput Struct 84(26-27):1641-1650. https://doi. org/10.1016/j.compstruc.2006.05.001

40. Gologanu M, Leblond JB, Devaux J (1993) Approximate models for ductile metals containing nonspherical voids - case of axiszmmetrical prolate ellipsoidal cavities. J Mech Phys Solids 41(11):1723-1754

41. Gao X, Wang T, Kim J (2005) On ductile fracture initiation toughness: effects of void volume fraction, void shape and void distribution. Int J Solids Struct 42(18-19):5097-5117. https://doi.org/10. 1016/j.ijsolstr.2005.02.028

42. Nahshon K, Hutchinson JW (2008) Modification of the Gurson model for shear failure. Eur J Mech A-Solids 27(1):1-17. https:// doi.org/10.1016/j.euromechso1.2007.08.002

43. Tvergaard V (1981) Influence of voids on shear band instabilities under plane-strain conditions. Int J Fract 17(4):389-407

44. Tvergaard V (1982) On localization in ductile materials containing spherical voids. Int J Fract 18(4):237-252

45. Tvergaard V, Needleman A (1984) Analysis of the cup-cone fracture in a round tensile bar. Acta Metall 32(1):157-169

46. Wen J, Huang Y, Hwang KC, Liu C, Li M (2005) The modified Gurson model accounting for the void size effect. Int J Plast 21(2): 381-395. https://doi.org/10.1016/j.ijplas.2004.01.004

47. Xue L (2008) Constitutive modeling of void shearing effect in ductile fracture of porous materials. Eng Fract Mech 75(11): 3343-3366. https://doi.org/10.1016/j.engfracmech.2007.07.022

48. Zhou J, Gao X, Sobotka JC, Webler BA, Cockeram BV (2014) On the extension of the Gurson-type porous plasticity models for prediction of ductile fracture under shear-dominated conditions. Int $\mathrm{J}$ Solids Struct 51(18). https://doi.org/10.1016/j.ijsolstr.2014.05.028

49. Malcher L, Mamiya EN (2014) An improved damage evolution law based on continuum damage mechanics and its dependence on both stress triaxiality and the third invariant. Int J Plast 56. https://doi. org/10.1016/j.ijplas.2014.01.002

50. Teng X (2008) Numerical prediction of slant fracture with continuum damage mechanics. Eng Fract Mech 75(8):2020-2041. https:// doi.org/10.1016/j.engfracmech.2007.11.001

51. Niazi MS, Wisselink HH, Meinders T, Huetink J (2012) Failure predictions for DP steel cross-die test using anisotropic damage. Int J damage Mech 21(5):713-754. https://doi.org/10.1177/ 1056789511407646

52. Saanouni K (2006) Virtual metal forming including the ductile damage occurrence. J Mater Process Technol 177(1-3). https:// doi.org/10.1016/j.jmatprotec.2006.03.226

53. Brunig M, Chyra O, Albrecht D, Driemeier L, Alves M (2008) A ductile damage criterion at various stress triaxialities. Int J Plast 24(10):1731-1755. https://doi.org/10.1016/j.ijplas.2007.12.001

54. Chow CL, Jie M (2009) Anisotropic damage-coupled sheet metal forming limit analysis. Int J damage Mech 18(4):371-392. https:// doi.org/10.1177/1056789508097548

55. Li H, Fu MW, Lu J, Yang H (2011) Ductile fracture: experiments and computations. Int J Plast 27(2):147-180. https://doi.org/10. 1016/j.ijplas.2010.04.001

56. Luo M, Dunand M, Mohr D (2012) Experiments and modeling of anisotropic aluminum extrusions under multi-axial loading - part II: ductile fracture. Int J plasticity 32-33:36-58. https://doi.org/10. 1016/j.ijplas.2011.11.001

57. Novokshanov D, Döbereiner B, Sharaf M, Münstermann S, Lian J (2015) A new model for upper shelf impact toughness assessment with a computationally efficient parameter identification algorithm. Eng Fract Mech 148:281-303. https://doi.org/10.1016/j. engfracmech.2015.07.069

58. Liu W, Lian J, Münstermann S, Zeng C, Fang X (2020) Prediction of crack formation in the progressive folding of square tubes during dynamic axial crushing. Int J Mech Sci 176:105534. https://doi.org/ 10.1016/j.ijmecsci.2020.105534

59. Shen F, Münstermann S, Lian J (2020) Investigation on the ductile fracture of high-strength pipeline steels using a partial anisotropic damage mechanics model. Eng Fract Mech 227:106900. https://doi. org/10.1016/j.engfracmech.2020.106900

60. He J, Lian J, Golisch G, He A, Di Y, Münstermann S (2017) Investigation on micromechanism and stress state effects on cleavage fracture of ferritic-pearlitic steel at $-196^{\circ} \mathrm{C}$. Mater Sci Eng A 686:134-141. https://doi.org/10.1016/j.msea.2017.01.042

61. Suraratchai M, Limido J, Mabru C, Chieragatti R (2008) Modelling the influence of machined surface roughness on the fatigue life of aluminium alloy. Int J Fatigue 30(12). https://doi.org/10.1016/j. ijfatigue.2008.06.003

62. Paul SK (2013) Real microstructure based micromechanical model to simulate microstructural level deformation behavior and failure initiation in DP 590 steel. Mater Des 44. https://doi.org/10.1016/j. matdes.2012.08.023

63. Uthaisangsuk V, Münstermann S, Prahl U, Bleck W, Schmitz HP, Pretorius T (2011) A study of microcrack formation in multiphase steel using representative volume element and damage mechanics. Comput mater Sci 50(4):1225-1232. https://doi.org/10.1016/j. commatsci.2010.08.007

64. Vajragupta N, Uthaisangsuk V, Schmaling B, Münstermann S, Hartmaier A, Bleck W (2012) A micromechanical damage simulation of dual phase steels using XFEM. Comput Mater Sci 54:271279. https://doi.org/10.1016/j.commatsci.2011.10.035

65. Zhao YW, Tryon R (2004) Automatic 3-D simulation and microstress distribution of polycrystalline metallic materials. Comput Methods Appl Mech Eng 193(36-38):3919-3934

66. BSI BSI (1996) Geometrical product specifications (GPS) - surface texture: profile method - metrological characteristics of phase correct filters. Iso 11562

67. ISO (2011). ISO 16610-21:2011(en), Geometrical product specifications (GPS) - Filtration - Part 21: Linear profile filters: Gaussian filters. iso

68. ISO (2015). ISO 16610-61:2015, Geometrical product specifications (GPS) - Filtration - Part 61: Linear areal filters: Gaussian filters. iso

69. Beuth (2009). DIN EN ISO 6892-1:2009-12 - Zugversuch - Teil 1: Prüfverfahren bei Raumtemperatur / tensile testing - part 1: method of test at room temperature. Beuth

70. Münstermann S, Langenberg P, Dahl W, Eisele U, Roos E (2004) Der Kurzrisseffekt bei der bruchmechanischen Prüfung. MP Materialprüfung 46(10):501-505

71. ISO (2016). ISO 16610-31:2016, Geometrical product specifications (GPS) - Filtration - Part 31: Robust profile filters: Gaussian regression filters

Publisher's note Springer Nature remains neutral with regard to jurisdictional claims in published maps and institutional affiliations. 